\title{
Effectiveness of Simulation linked Problem Based Learning on Nursing College Students in South Korea
}

\author{
Mi-Hye Lim \\ Professor, \\ Department of Nursing Science, \\ Joongbu University, South Korea
}

Doi: 10.36941/ajis-2020-0o18

\begin{abstract}
The purpose of this study was to investigate the effect of simulation with problem based learning on learning self-efficacy, critical thinking disposition and problem solving ability on nursing students in South Korea. The study was used one group pre-post test design, conducted on 65 nursing students in C Province and from August 27th to November 14th 2018. The study purpose was explained to the subject and a written informed consent was obtained. The participants were divided into three classes of five groups each. Every group consisted of four to five students. Simulation linked problem based learning was conducted for a total of nine hours: three hours a week over a period of three weeks. The differences between self-efficacy, problem solving ability, and critical thinking tendency were examined before and after simulation linked problem based learning. Data were collected through a self-reported questionnaire and analyzed using t-test, paired-t-test, Pearson's correlation. The scores of learning self-efficacy and critical thinking disposition after the simulation with problem-based learning were significantly higher than before simulation with problem-based learning. Learning self-efficacy after S-PBL had a significant positive correlation with critical thinking tendency and problem-solving ability, and there was a correlation between critical thinking tendency and the degree of problem-solving ability. As simulation with problem based learning improves the learning selfefficacy and critical thinking disposition of nursing students, it is necessary to develop scenarios based on various clinical cases and to operate a learning method to experience the problem-solving process.
\end{abstract}

Keywords : critical thinking disposition, learning self-efficacy, nursing students, problem based learning, simulation

\section{Introduction}

The issue of nursing shortage in medical institutions in South Korea has been repeatedly raised. As a result, the government is making efforts to expand the supply of new nurses. There are several causes of nurse shortages, but one of the most important reasons is that many nurses quit within a year of starting work. Thus, it is important to lower the rate of resignation of new nurses in order to solve the problem of nursing shortage in medical institutions (Ministry of Welfare, 2019). The main reason why new nurses quit is the difference between the training environment at school and the hospital environment, making it difficult to apply their knowledge to patients in actual clinical practice (Kim, Lee, Cho, \& Kim, 2013; Kim \& Kim, 2016). As a result, new nurses are not confident in their work.

Universities must equip nursing students with the skills required to display satisfactory clinical performance, and simulation education is an effective tool in this regard.

In South Korea, simulation education is mainly conducted in intensive care nursing, adult 
nursing, psychiatric nursing, integrated nursing education courses, basic nursing, and maternity nursing (Kim \& Ham, 2015). Previous studies have shown that S-PBL results in improved problemsolving abilities and learning satisfaction. Since experience of neonatal nursing is difficult to gain in clinical training, simulation education on the theme of newborns is necessary in nursing schools.

However, there has not been much neonatal simulation education in South Korea. In high-risk newborn nursing, it is meaningful to confirm the effects of S-PBL. The purpose of this study was to confirm the effects of S-PBL on learning self-efficacy, critical thinking tendency, and problem-solving ability in high-risk newborn nursing students, and to grasp the correlations between them. I would like to provide basic materials for programs to improve the clinical performance of nursing students, and ultimately contribute to improving the clinical adaptation of new nurses.

\section{$1.1 \quad S-P B L$}

Simulation education is a teaching method that presents situations similar to those encountered in actual hospital settings, giving students an opportunity to understand the processes involved in problem-solving in the professional environment (Kim, 2017). Simulation education allows students to learn standardized procedures and gain the necessary experience (Kim \& Han, 2015). It has the advantage of providing safe and repetitive exposure to the difficult situations experienced in actual clinical practice.

Simulation leads to improvements in clinical performance through immediate feedback between teacher and learner in the problem-solving process. In addition, it has been shown to improve confidence among nurses as well as nursing students (Kim, 2017; Kim \& Han, 2015). However, despite these benefits, if a learner is insufficiently prepared, does not have an adequate understanding of the scenario, or is unfamiliar with the contents and techniques of simulation, the result is a feeling of burden, leading to a decrease in the educational effect (Kim \& Yu, 2017).

There is a method that can counter this burden and enhance the educational effect: simulationlinked problem-based learning (S-PBL). Without the simulation aspect, PBL is learner rather than teacher-centered; problems are approached on the basis of knowledge, skills, and experience, and ultimately resolved through discussions and collaborative activities with colleagues (Hwang, 2003).

Combining simulation and PBL, in S-PBL, students learn effective troubleshooting while being trained in professional nursing techniques (Kim, 2017). S-PBL is a problem-solving activity that utilizes examples reflecting actual situations. In the context of nursing education, it helps nurses develop the problem-solving skills necessary to solve the various health problems encountered in clinical practice (Yang \& Lee, 2018). Nursing students who have been exposed to simulations of clinical scenarios they have not personally encountered have an advantage with regard to solving various patient health problems after graduation.

In order for S-PBL to be effective, problem situations must have the characteristics of real clinical scenarios.

\section{Research Method}

\subsection{Research Design}

This experimental study employed a pre-post single group design to verify the effects of S-PBL on learning self-efficacy, critical thinking tendency, and problem-solving ability in nursing students.

\subsection{Participants}

The participants were students enrolled in a four-year nursing course in D City in South Korea with no prior experience of simulation education, who attended a simulation training course in the second semester of 2018. The researcher explained the purpose of the study, subsequent to which the 
participants provided written informed consent. The estimated sample size was calculated using $\mathrm{G}^{*}$ Power 3.1 (Buchner, 2007). The minimum required sample size was 45 . Ultimately, 65 nursing students participated in the study.

\subsection{Research Instruments}

Learning self-efficacy refers to an individual's belief that they can adequately employ newly learned educational contents (Ayres, 2005). In this study, learning self-efficacy was measured using a tool developed by Ayres (2005) and modified by Park (2012). In this 10-item tool, each item is rated on a five-point Likert scale, and the higher the score, the higher the learning self-efficacy. Regarding the instrument's reliability, Cronbach's a was 0.94 at the time of development and 0.93 in this study.

Critical thinking tendency refers to the motivation, desire, and attitude to think analytically. In this study, the 27-item tool developed by Yoon (2004) was used. Each item is rated on a five-point Likert scale, and the higher the score, the higher the critical thinking tendency. Cronbach's a was 0.84 at the time of development and 0.84 in this study.

Problem-solving ability refers to the capability to recognize and resolve problems by seeking and organizing knowledge and information (Park \& Woo, 1999). In this study, a modified version of Park and Woo's (1999) problem-solving process test tool was used. This tool covers five areas: problem finding, definition, solution design, implementation, and problem-solving review, with a total of 25 questions. Each item is measured on a five-point Likert scale, and the higher the score, the higher the problem-solving ability. Cronbach's a was 0.89 at the time of development and 0.90 in this study.

\subsection{S-PBL Education}

\subsubsection{Development of S-PBL module}

The S-PBL module was tailored for the care of high-risk neonates in neonatal intensive care units, where nursing students have few practical opportunities and observation and direct care are difficult. The module included the knowledge, attitudes, and skills necessary for judging newborns' health status and solving problems.

The scenario, regarding the apnea situation immediately after birth, was developed in consultation with one child nursing professor, two neonatal intensive care nurses, and one neonatal specialist. In this scenario, premature infants with a 30 -week gestation period had apnea immediately after delivery, with decreased pulse and respiratory rates and changes in skin color. The first step was for nurses to check the overall physical condition and pulse of newborns.

The nursing intervention algorithm based on the study of Wyckoff et al., (2015) involves coping with changing patient status in high-risk neonates with apnea. The next step in the algorithm is to determine whether nurses can recognize and assess the apnea status of high-risk neonates, implement necessary nursing interventions in apnea situations, and work effectively with teams in high-risk neonatal emergency care.

The next step was debriefing, which involved three stages. In the first stage, the nursing students talked about the newborns' conditions and their professional evaluation of the situation, the most important aspect, and the emotions they experienced while performing nursing care The second phase involved an analysis of whether the nursing students had previously experienced similar situations, whether the present situation elicited any different thoughts from previous situations, and whether the actions or judgments in this situation would differ from those made in previous situations. In the third phase, students were given time to reflect on whether their newly gained experiences could be applied in real clinical settings after graduation or whether they needed further exposure. 


\subsubsection{Operation of $S-P B L$}

S-PBL was conducted for a total of nine hours: three hours a week over a period of three weeks. The participants were divided into three classes of five groups each. Every group consisted of four to five students.

In the first week, we introduced PBL and the problem-solving process. The instructor presented the required pre-learning material so that the students could understand the clinical situation.

In the second week, students were encouraged to read scenarios and ask questions and engage in step-by-step discussions so that they could identify and solve problems through critical thinking. Scenarios for emergencies immediately after the birth of premature infants were presented as primary data, and emergency scenarios requiring neonatal resuscitation were presented as secondary data. Step-by-step discussion of nursing problem identification and intervention priorities was conducted. After setting the nursing priorities, the group practiced self-regulation of nursing techniques needed to solve the problem. During the simulation, two instructors helped students practice nursing skills and situational analysis.

In the third week, emergency care was implemented for the apnea situation of premature infants with 30 weeks of gestation using the neonatal simulator. Simulation operation evaluation, post-simulation activities, and debriefings were conducted. Simulation operation was randomly decided. The simulation for each group lasted 20 minutes, and the simulation training process was recorded for all videos. Before the simulation exercise, the nursing students were informed that the course was to be recorded, and written informed consent was obtained. Nursing skills and communication were evaluated by altering the premature infant's situation according to the nursing skill that was to be evaluated. When one group participated in the simulation run, the others gave an autonomous training on nursing skills necessary to solve the problem. After the simulation, each group underwent a 20-minute debriefing based on the experience, strengths, and weaknesses of each person. They were complimented for their contribution in implementing the scenario and given advice regarding how they could improve.

\subsection{Data Collection}

The study was conducted from August 27 to September 14, 2018. Data were collected through a selfreported questionnaire. Participants completed a pre-questionnaire before the simulation and a postquestionnaire after the debriefing. Regarding ethical considerations, the study was conducted after receiving consent forms from the students, who were given an explanation of the purpose and methods of the study, as well as data collection procedures. They were also informed that the data would only be used for this study, that they could withdraw their participation at any time, and that there would be no repercussions for withdrawing from the study. Collected data were processed anonymously by separating consent form and questionnaire.

\subsection{Data Analysis}

Data were analyzed using SPSS 21.o. The differences in participants' learning self-efficacy, critical thinking tendency, and problem-solving ability before and after S-PBL were analyzed by t-test. The relationship between self-learning efficacy, critical thinking tendency, and problem-solving ability was examined by using Pearson's correlation coefficient.

\section{Results and Discussion}

This study was conducted to verify the effectiveness of S-PBL with regard to learning self-efficacy, critical thinking tendency, and problem-solving ability in high-risk newborn nursing students, and to grasp the correlations between these variables. In this study, a scenario based on actual cases was 
used in consultation with a clinical expert in S-PBL class.

The subjects of this study had no experience of simulation training, and most of them were $76.9 \%$ of female students, $23.1 \%$ more than male students. In average grade, $3.5-3.9$ point (43.1\%) were the most and below 3.5 point ( $9.2 \%)$ were the least (Tableı)

Table 1: General Characteristics of the subject

\begin{tabular}{llcc}
\hline Variable & & Respondent & Percentage \\
\hline \multirow{2}{*}{ Gender } & Male & 15 & 23.1 \\
\cline { 2 - 4 } & Female & 50 & 76.9 \\
\hline \multirow{2}{*}{ Average grade } & $3.0<$ & 6 & 9.2 \\
\cline { 2 - 4 } & $3.0-3.4$ & 21 & 23.3 \\
\cline { 2 - 4 } & $3.5-3.9$ & 28 & 43.1 \\
\hline
\end{tabular}

\subsection{Difference before and after S-PBL Education}

The pre- and post-S-PBL education results showed that learning self-efficacy increased from 4.02 points to 4.30 points $(\mathrm{t}=-2.976, \mathrm{p}=.004)$. Critical thinking tendency increased from 3.62 points to 3.81 points $(\mathrm{t}=-3.252, \mathrm{p}=.002)$. Problem-solving ability decreased from 3.89 points to 3.78 points and was not statistically significant $(\mathrm{t}=1.066, \mathrm{p}=.291)$ (Tablez).

Table 2: Effectiveness of Learning Self-Efficacy, Critical Thinking Disposition and Problem Solving Ability

\begin{tabular}{lcccc}
\hline \multirow{2}{*}{ Variable } & Before & After & $\mathrm{t}$ & $\mathrm{p}$ \\
\cline { 2 - 4 } Learning self-efficacy & $\mathrm{M} \pm \mathrm{SD}$ & $\mathrm{M} \pm \mathrm{SD}$ & & \\
\hline Critical thinking disposition & $4.02 \pm .53$ & $4.30 \pm .52$ & -2.976 & .004 \\
\hline Problem solving ability & $3.62 \pm .35$ & $3.81 \pm .34$ & -3.252 & .002 \\
\hline
\end{tabular}

In this study, learning self-efficacy increased after S-PBL. Consistent with the results of Cho and Kang's (2019) study on nursing students, it indicates that PBL improves students' academic efficacy (Yang \& Lee, 2018), while simulation practice improves both self-efficacy and self-confidence (Yoo, 2013). Also, critical thinking tendency increased after S-PBL. This is consistent with the results of a study by Kim and Chun (2018). The critical thinking tendency is expanded through the process of analyzing and discussing the situation to solve problems, and reflects improvement through selfpractice and repetitive learning (Kim \& Kim, 2016). However, problem-solving ability was not significantly difference before and after S-PBL education. In studies by Kim and Chun (2018), Kim and Kim (2016), and Park and Choi (2018), problem-solving aggressiveness increased after S-PBL in nursing students. However, like the present study, Cho and Hwang (2016) and Kim (2017) reported no difference in problem-solving ability before and after S-PBL. Such variations in results can be attributed to differences in scenarios used across studies; while the scenarios in most previous studies have involved adult patients, this study focused on neonates. Therefore, it is necessary to repeat the study to confirm the effect on problem-solving ability by using a wider range of subjects. 
3.2 Correlation between Learning Self-Efficacy, Critical Thinking, and Problem-Solving Ability after SPBL Education

Learning self-efficacy had positive correlations with critical thinking disposition $(\mathrm{r}=.482$, $\mathrm{p}<.001)$ and problem- solving ability $(\mathrm{r}=.483, \mathrm{p}<.001)$. Critical thinking tendency and problem-solving ability $(\mathrm{r}=$ $.694, \mathrm{p}<.001$ ) were also positively correlated (Table 3 ).

Table 3: Correlation of Learning Self-Efficacy, Critical Thinking Disposition and Problem Solving Ability

\begin{tabular}{lccc}
\hline Variable & $\begin{array}{c}\text { Learning } \\
\text { self-efficacy } \mathrm{r}(\mathrm{p})\end{array}$ & $\begin{array}{c}\text { Critical thinking } \\
\text { disposition } \mathrm{r}(\mathrm{p})\end{array}$ & $\begin{array}{c}\text { Problem solving } \\
\text { ability } \mathrm{r}(\mathrm{p})\end{array}$ \\
\hline Learning self-efficacy & 1 & & \\
\hline Critical thinking disposition & $.482(<.001)$ & 1 & $\mathbf{1}$ \\
\hline Problem solving ability & $.483(<.001)$ & $.694(<.001)$ & $\mathbf{1}$ \\
\hline
\end{tabular}

This result is in accordance with Kim and Chun's (2018) finding that learning confidence and problem- solving ability showed a positive relationship. PBL is a teaching method in which autonomous learning is strengthened by motivating the learner to learn spontaneously. Simulation practice was conducted after students had gained motivation through pre-learning; therefore, learning self-efficacy rose in the process of solving nursing problems in cooperation with colleagues through team-specific learning and discussion. Learning self-efficacy is the confidence that one is good at learning, and it is closely related to the ability to perform clinical practice. Accordingly, students with high learning self-efficacy are more confident in their ability to work in clinical situations (Kim \& Kang, 2016); thus, it is important to increase students' learning self-efficacy through S-PBL.

In this study, critical thinking tendency pointed toward the relationship between problemsolving ability, which is similar to a previous study (Hwang \& Kim, 2016). In S-PBL, in order to improve students' problem-solving skills, instructors should provide examples that are appropriate to the students' level of learning, and students should work with their peers and take the lead in problem solving. In previous studies, nursing students displayed better clinical nursing performance during school-based S-PBL than hospital-based clinical practice education (Hong \& Kim, 2016; Lee, 2017). This indicates that in order to improve the clinical performance of nursing students, S-PBL should be further activated in nursing education institutions.

Most of the scenarios used in simulations center on topics that are difficult for nursing students to experience in the clinical field or difficult to practice because of their student status (Kim, 2017). In addition, most of the scenarios used in the simulation practice center on topics that are difficult for nursing students to experience in the clinical field or difficult to practice due to student status (Kim \& Chun, 2018; Hwang, 2016). In the future, simulation education should go beyond simply presenting topics that students do not generally get to experience and must focus on the general areas where students experience difficulty in clinical (Hong \& Kim, 2016; Lee, 2017).

In this study, it was confirmed that simulation practice education improved self-efficacy and critical thinking tendency by allowing learners to work together with their peers to solve nursing problems. Therefore, in order to improve the clinical performance of nursing students, S-PBL should be given a new impetus. However, as this study verified the effects of simulation practice in the context of high-risk neonatal cases in students of a single university nursing college, attempts to generalize the results must be undertaken with caution. Further, the effectiveness of practical training must be confirmed through repeated research. 


\section{Conclusion}

This study was conducted to verify the effectiveness of S-PBL in high-risk newborn nursing, and confirmed the differences in learning self-efficacy, critical thinking tendency, and problem-solving ability of nursing students through problem-solving learning based on emergency scenarios. In this study, a scenario based on actual cases was used in consultation with a clinical expert in S-PBL class. The participants were divided into three classes of five groups each. Every group consisted of four to five students. S-PBL was conducted for a total of nine hours: three hours a week over a period of three weeks. As a result of this study, while learning self-efficacy and critical thinking tendency in nursing students increased significantly, there was no significant difference in problem-solving ability. Learning self-efficacy after S-PBL had a significant positive correlation with critical thinking tendency and problem-solving ability, and there was a correlation between critical thinking tendency and the degree of problem-solving ability. It was confirmed that S-PBL improves self-learning efficacy and critical thinking tendency of nursing students. Since students' self-efficacy and critical thinking tendency contribute to the clinical performance of new nurses after graduation, S-PBL education should be activated to improve this, In order to maximize the effectiveness of S-PBL, it is necessary to develop scenarios based on various clinical cases and to operate a learning method to experience the problem-solving process. Further research is required to confirm the effects of practical education.

\section{References}

Ayres, H. W. (2005). Factors related to motivation to learn and motivation to transfer learning in a nursing population (Order No. 3162411). Available from ProQuest Central; ProQuest Dissertations \& Theses Global. (305425864). Retrieved from https://search.proquest.com/docview/305425864?accountid=45509

Buchner, A., Faul, F., Erdfelder, E., \& Lang, A. G. (2007). G*Power 3 : A flexible s statistical power analysis program for the social, behavioral, and biomedical sciences. Behavior Research Methods, 39(2), 175-191.

Cho, O. H., \& Hwang, K. H. (2016). The effect of education based on simulation with problem-based learning on nursing students' learning motivation, learning strategy, and academic achievement. The Journal of the Korea Contents Association, 16(7), 640-650

Cho, Y. M., \& Kang, S. R. (2019). Effect of simulation-problem based learning education on self-determined motivation, academic self-efficacy and self-regulated learning in nursing students. Journal of learnerCentered and Instruction, 19(11)25-41

Hong, E. J., \& Kim, H. Y. (2016). The Impact of Simulation-based Learning in Undergraduate Courses on the Problem Solving and Clinical Competence for New Nurses. The Journal of the Korea Contents Association, 16(10), 617-626

Hwang, E. H., \& Kim, K. H. (2016). Differences in critical thinking disposition and life-skills of nursing students comparison of high school tracks. Journal of Korean Society for Wellness, 11(1), 59-68

Hwang, S. Y. (2003). Effects of problem-based learning on the knowledge achievement, critical thinking ability, attitude and motivation toward learning of nursing students, Unpublished theses, JunNam University

Kim, H. J., \& Chun, I. H. (2018). The effect of problem-based learning and simulation practice convergence education for nursing students. Journal of the Korea Convergence Society, 9(7), 355-364

Kim, J. S., \& Y. H. Kim. (2016). The effects of simulation practice education applying problem-based learning on problem solving ability, critical thinking and learning satisfaction of nursing students. The Journal of the Korea Contents Association, 16(12), 203-212

Kim, S. Y. (2017). Effect of simulation-based education by applying problem based learning on self-directed learning, problem solving skills, satisfaction of learning. Journal of Learner-Centered and Instruction, 17(10), 313-330

Kim, S. O., \& Kang, B. H. (2016). The influence of nursing students' learning experience, recognition of importance and learning self-efficacy for core fundamental nursing skills on their self-confidence. Journal of the Korea Academia-Industrial Cooperation Society, 17(8), 172-182

Kim, G. L., Lee, H. J., Cho, Y.S. \& Kim, M. H. (2013). The experience of turnover decision making in new graduate nurses. Journal of Qualitative Research, 14(1), 22-33

Kim, H. S., \& Yu, S. Y. (2017). Effects of simulation-based asthma pediatric care: education on knowledge and clinical performance of nursing students. Journal of Korea Society for Simulation in Nursing, 5(2), 45-54 
Kim, S. Y. (2017). Effect of simulation-based education by applying problem based learning on self-directed learning, problem solving skills, satisfaction of learning. Journal of leaner-Centered Curriculum and Instruction, $17(10), 13-330$

Kim, S. H., \& Y. S. Ham. (2015). A meta-analysis of the effect of simulation based education - Korean nurses and nursing students. Journal of Korean Academic Society of Nursing Education, 21(3), 308-319

Kim, Y. M., \& Kim, S. N. (2016). The convergence study of experience of turnover in new graduate nurses within one year. Journal of Korea Convergence Society, 7(4), 97-106

Lee, O. S. (2017). The effects of simulation-based practice on critical thinking disposition, communication skill, and clinical performance for nursing students. Journal of the Korea Academia-Industrial Cooperation Society, $18(4), 93-100$

Ministry of Health and Welfare. Nurse working environment and treatment improvement measures. [Internet]. Seoul: Ministry of Health and Welfare, [cited 2018 Mar 20], Available From: http://www.mohw.go.kr/react/al/salo3o1vw.jsp?PAR_MENU_ID=04\&MENU_ID=0403\&CONT_SEQ=344262 \&page $=1$ (accessed Jun. 1, 2019)

Park, J. H., \& Woo, O. H. (1999). The effects of pbl(problem-based learning) on problem solving process by learner's metacognitive level. Journal of Educational Technology, 15(3), 55-81

Park, M. J., \& Choi, D. W. (2018). The effect of simulation integrated with problem based learning on system thinking, learning flow, proactivity in problem solving and performance ability for medication in nursing students. Journal of Digital Convergence, 16(8), 221-231

Park, S. Y. (2012). The effect of using standardized patients in psychiatric nursing practical training on nursing college students, Unpublished thesis, Chosun University

Wyckoff, M. H., Aziz, K., Escobedo, M. B., Kapadia, V. S., Kattwinkel, J. Perlman J. M. et al. (2015). Neonatal Resuscitation: 2015 American heart association guidelines update for cardiopulmonary resuscitation and emergency cardiovascular care. Circulation, 32(2), $\mathrm{S}_{543}-\mathrm{S}_{560}, 2015$.

Yang, S. H., \& Lee, J. E. (2018). The effects of problem based learning and team based learning in nursing: a metaanalysis. Journal of leaner-Centered Curriculum and Instruction, 18(23), 187-211

Yoo. S. Y. (2013). Development and effects of a simulation-based education program for newborn emergency care. Journal of Korean Academy of Nursing, 43(4), 468-477

Yoon, J. (2004). Development of an Instrument for the Measurement of Critical Thinking Disposition: In Nursing. Unpublished theses, Catholic University. 